\title{
Treat-to-Target Strategies in Rheumatoid Arthritis: a Systematic Review and Cost-Effectiveness Analysis
}

\author{
Emma Stefania Hock ${ }^{1}$ (D) - Marrissa Martyn-St James ${ }^{1}$ (D) $\cdot$ Allan Wailoo $^{1}$ (D) $\cdot$ David L. Scott $^{2}$ (D) Matt Stevenson $^{1}$ (D) \\ Andrew Rawdin ${ }^{1}$ (D) Emma L. Simpson ${ }^{1}$ (D) $\cdot$ Naila Dracup $^{3}$ (D) $\cdot$ Adam Young $^{4}$ (D)
}

Accepted: 1 January 2021 / Published online: 25 January 2021

(C) The Author(s) 2021

\begin{abstract}
To systematically review clinical and health economic impacts of treat-to-target (TTT) strategies in patients with rheumatoid arthritis (RA) managed in specialist units, compared with routine care. Sixteen and seven electronic databases were searched for clinical RCTs and cost-effectiveness respectively. Study selection, data extraction and quality assessment (Cochrane Collaboration risk of bias criteria) were performed. Evidence was reported by (1) TTT vs. usual care; (2) comparison of different treatment protocols against each other; (3) comparison of different targets against each other. Narrative synthesis was undertaken and conclusions drawn on a trial by trial basis, due to study heterogeneity. Twenty-two RCTs were included. Sixteen were at high risk of bias, five unclear and one low risk. Three trials showed TTT to be more effective than usual care in terms of remissions, in some or all comparisons, whereas one other trial reported no significant difference. Two trials showed TTT to be more effective than usual care in terms of low disease activity (LDA), in some or all comparisons, whereas two trials reported little difference. Some evidence suggests that TTT strategies involving combination therapy can achieve more remissions than those involving monotherapy, but little impact of alternative treatment targets on remission or LDA. Overall, there is evidence that TTT increases remissions in early RA and mixed early and established RA populations, and increases LDA in established RA. Although results varied, typically TTT was estimated to be more cost-effective than usual care. No target appears more effective than others.
\end{abstract}

Keywords Rheumatoid arthritis $\cdot$ Treat-to-target $\cdot$ Tight control $\cdot$ Systematic review

\section{Introduction}

Rheumatoid arthritis (RA), characterised by persisting joint inflammation and pain, leads to joint damage, disability and poor quality of life, which incur high medical and societal costs [1-4]. In developed countries, between 0.5 and $1 \%$ of

Emma Stefania Hock

emma.hock@sheffield.ac.uk

1 School of Health and Related Research, University of Sheffield, Regent Court, 30 Regent Street, Sheffield S1 4DA, UK

2 Department of Rheumatology, King's College Hospital NHS Foundation Trust, Denmark Hill, Brixton, London SE5 9RS, UK

3 Centre for Contemporary Hospitality and Tourism, University of Derby, Kedleston Road, Derby DE22 1GB, UK

4 Department of Rheumatology, Centre for Lifespan and Chronic Illness Research, University of Hertfordshire, Hatfield AL10 9EU, UK adults have RA, and its long-term course means its prevalence rises with age [5].

Drug treatment for RA over the last two decades has focused on using disease-modifying anti-rheumatic drugs (DMARDs) with variable amounts of short-term glucocorticoids. Conventional synthetic DMARDs (csDMARDs), such as methotrexate, are widely used. They are often supplemented by biological DMARDs (bDMARDs), in particular tumour necrosis factor inhibitors such as etanercept [6]. bDMARDs are substantially more expensive than csDMARDs and are usually given in combination with methotrexate [7]. An additional new group of DMARDs, the Janus kinase inhibitors, has been available for a few years, but their use is minimal in the trial designs included in our systematic review.

The goal of DMARD treatment is to reduce disease activity, ideally by achieving remission or low disease activity (LDA). As csDMARD and bDMARDs can be used in combination and doses adjusted according to clinical response, the concept of "treat-to-target" (TTT) has grown in recent years, supported by international reports and guidelines [8-12]. Its 
components comprise (a) setting the target, which is usually remission or LDA; (b) assessing disease activity every 1-3 months using measures like the disease activity score for 28 joints (DAS28); and (c) increasing csDMARDs, bDMARDs, and Janus kinase inhibitors to facilitate achievement of the target, using short-term glucocorticoids if needed [7]. As TTT is a relatively new strategy, there is uncertainty about both its efficacy and its cost-effectiveness, although economic analysis using observational data provides some support [13].

bDMARDs are expensive drugs and their use in TTT incurs high costs to healthcare providers. There is consequently a strong case to assess the underlying health economic rationale for using TTT approaches. As the impact of TTT differs in early and established RA patients [8, 10], economic evaluations need to consider these populations separately. Although systematic reviews by Schoels et al. [9] and Stoffer et al. [11] assessed the evidence supporting TTT, neither evaluated its economic impact. There have also been several new trials reported since these reviews were completed. We have consequently undertaken a comprehensive systematic review of both the clinical and health economic impacts of TTT, including randomised controlled trials (RCTs) published up until 2020.

\section{Methods}

This review was commissioned by the NIHR HTA Programme (Project 14/17/01) [14]. The protocol is registered as PROSPERO CRD42015017336.

\section{Search Strategy}

We followed PRISMA principles (http://www.prismastatement.org/) (Supplement 1).

Initial searches involved MEDLINE, EMBASE, Cochrane Database of Systematic Reviews, Cochrane Central Register of Controlled Trials (CENTRAL), NHS Economic Evaluation Database (NHS EED), Health Technology Assessment Database (HTA), Database of Abstracts of Reviews of Effects (DARE), Web of Science Citation Index Expanded (WoS), Web of Science Citation Index and Conference Proceedings Index (WoS-CPI), EULAR (via Web of Science), ACR (via Web of Science) and ClinicalTrials.gov using terms for RA combined with TTT terms (after Schoels et al. [9]), and search filters for RCTs, systematic reviews and economic evaluations (Supplement 2).

A full systematic search was conducted from database inception to January 2016, refined by initial searches, on MEDLINE, EMBASE, CENTRAL, NHS EED, WoS, WoSCPI, BIOSIS Previews, CINAHL, Econlit, ClinicalTrials.gov, International Clinical Trials Registry Platform and NICE Evidence. Additional TTT and RCT free-text terms and economic evaluation filters were added (Supplement 2) to increase the search sensitivity. No date or language limits were applied. Records from initial and full searches were combined and duplicates removed. An update search was performed on Medline (via EbscoHOST) in November 2020. No date or language limits were applied. The results from the update search were de-duplicated against the original results.

\section{Inclusion and Exclusion Criteria}

RCTs (including cluster RCTs) examining the effectiveness of one or more TTT strategies to guide treatment decisions for individual patients compared with (1) usual care (no TTT strategies); (2) TTT strategy using an alternative treatment protocol; and (3) TTT strategy using an alternative target, on the proportion of patients achieving remission and LDA, and adverse effects, among adults with clinically diagnosed RA managed anywhere on the treatment pathway, were included. Sufficient description of the TTT strategy was required; meeting abstracts had to contain sufficient methodological details for critically appraising study quality. Included studies were limited to those published in the English language. Animal models, preclinical and biological studies, trials of personalised medicine, trials of other designs and trials designed to test an active drug against placebo, where both/all trial arms pursue the same target and treatment protocol, were excluded.

\section{Study Selection and Data Extraction}

One reviewer (MMSJ) examined titles and abstracts of retrieved records; 5\% were checked by another reviewer (ESH). Full texts of all studies included were examined by two reviewers, where necessary discrepancies were resolved by discussion involving a third reviewer. For the update search, all titles, abstracts and full texts were examined by one reviewer (ESH) and checked by another (ELS or MMSJ).

Three reviewers undertook data extraction (ESH, MMSJ, ELS). Each paper was extracted by one reviewer, unblinded to authors or journal, on data relevant to the decision problem, using a standardised form. Data on study, population and TTT characteristics, including adverse events (AEs), were extracted and checked by a second reviewer. Discrepancies were discussed and agreement was reached without needing to consult a third reviewer.

\section{Quality Assessment}

One reviewer (shared among ESH, MMSJ, ELS) assessed methodological quality of each RCT using Cochrane Collaboration risk of bias assessment criteria, evaluating sequence generation; allocation concealment; blinding of 
participants and personnel; blinding of outcome assessment; incomplete outcome data; and selective outcome reporting, each judged as high, low or unclear risk of bias [15]. We included three additional domains for cluster RCTs: recruitment bias (whether participants were recruited prior to clusters being randomised); risk of baseline differences between clusters; and attrition of clusters. We classified RCTs as overall 'low risk' of bias if they were rated as 'low' for each of three key domains - allocation concealment, blinding of outcome assessment and completeness of outcome data ( $>10 \%$ attrition [16]). RCTs at 'high risk' of bias for any of these domains were judged 'high risk' overall. RCTs neither being at 'high risk' for any domain, nor 'low risk' for all these domains, were judged 'unclear risk' overall. All quality assessments were checked by a second reviewer with discrepancies discussed and agreement reached.

\section{Data Synthesis}

Evidence of clinical effectiveness of TTT was organised by TTT comparisons: (1) TTT vs. usual care; (2) comparison of different treatment protocols; (3) comparison of different targets. Two trials not fitting this framework were examined separately [17-20]. Some trials made more than one comparison and appear under more than one category. Trials were further examined according to whether they used early or established RA populations $[8,10,21]$ using definitions of early and established RA outlined in the trials; where no definition was provided a 3-year cut-off was used [21].

\section{Results}

\section{Study Selection}

Forty-nine papers reporting 22 RCTs were included from 17,631 records reviewed (Fig. 1); 42 papers reporting 16 RCTs from the original searches, and seven papers reporting six new RCTs and one updated RCT from the update searches. We excluded 17,418 on titles and abstracts: 213 publications were reviewed in detail and 164 papers describing 72 studies were excluded (107 not TTT, 18 not RCTs; 10 reporting no relevant outcomes; 29 excluded for diverse reasons).

\section{Study Characteristics}

The 49 papers described 22 trials of 5990 RA patients. The trials spanned four categories (Table 1) based on their main features. Eight trials (1977 patients) compared TTT with usual care [22-29]; seven trials (2418 patients) compared different treatment protocols [30-36]; six trials (1758 patients) compared different treatment targets [24, 26, 35, 37-39]; four trials
(1143 patients) made other comparisons of conventional with intensive therapy $[14,17,19,20]$. Thirteen trials studied early RA patients [17, 24, 25, 30-39]; five studied established RA patients [19, 26-28, 40]; and four studied early and established RA [20, 22, 23, 29]. Fifteen trials involved controls receiving less intensive treatment $[17,19,20,22-30,33$, $36,40]$, including four with groups receiving different intensive treatment strategies $[24,26,30,36]$. Five trials compared different intensive treatments without controls receiving less intensive therapy [30-32, 34, 35]. Three trials compared two different targets without controls receiving less intensive therapy [37-39]. Four trials were cluster randomised [22, 26, 27, $29]$ and 18 were not $[17,19,20,23-25,28,30-40]$.

\section{Risk of Bias}

Twelve RCTs were judged at overall high risk of bias [17, 19, $20,24,28,31,33,35-39]$, five at overall unclear risk of bias $[25,30,32,34,40]$ and one at overall low risk of bias [23]. None were judged at high risk of bias for random sequence generation or allocation concealment; 13 had high risk of bias for blinding of participants and personnel [17, 19, 20, 23-25, 31-34, 38-40]; eight for blinding of outcome assessment [19, 20, 24, 31, 33, 37-39]; eight from reporting withdrawals > $10 \%[17,19,24,28,35,36,39,40]$; and five had high risk of bias as some outcomes reported in either the protocol $[20,25$, $28,32]$ or the methods section [35] were omitted from the results (Supplement 3).

All four cluster RCTs were considered at overall high risk of bias [22, 26, 27, 29]. Three were judged at high risk of bias for blinding of participants and personnel [22, 26, 27], one had high risk of bias for blinding of outcome assessment [22], all four had high risk of attrition bias [22, 26, 27, 29], one had high risk of bias for selective reporting [26], two had high risk of cluster recruitment bias (participants were recruited after clusters were randomised) $[26,27]$ and two had high risk of bias for cluster attrition (outcomes were limited to a subset of original clusters randomised) [27, 29] (Supplement 3).

\section{Clinical Effectiveness}

Heterogeneity across populations, comparisons, targets, treatment protocols and outcomes precluded meta-analysis. Trial findings were synthesised narratively focusing on proportions of patients achieving end-point remissions in 18 trials, and LDA or equivalent in four trials not reporting remissions (Table 2 and Fig. 2).

\section{TTT vs Usual Care}

Four of the eight trials reported remissions: all found more remissions with intensive treatment; differences were significant in three trials. The TICORA trial [23] (two groups, early 
Fig. 1 Flow diagram of study selection for systematic review of TTT strategies in rheumatoid arthritis

LDA low disease activity, RCT randomised controlled trial, TTT treat-to-target

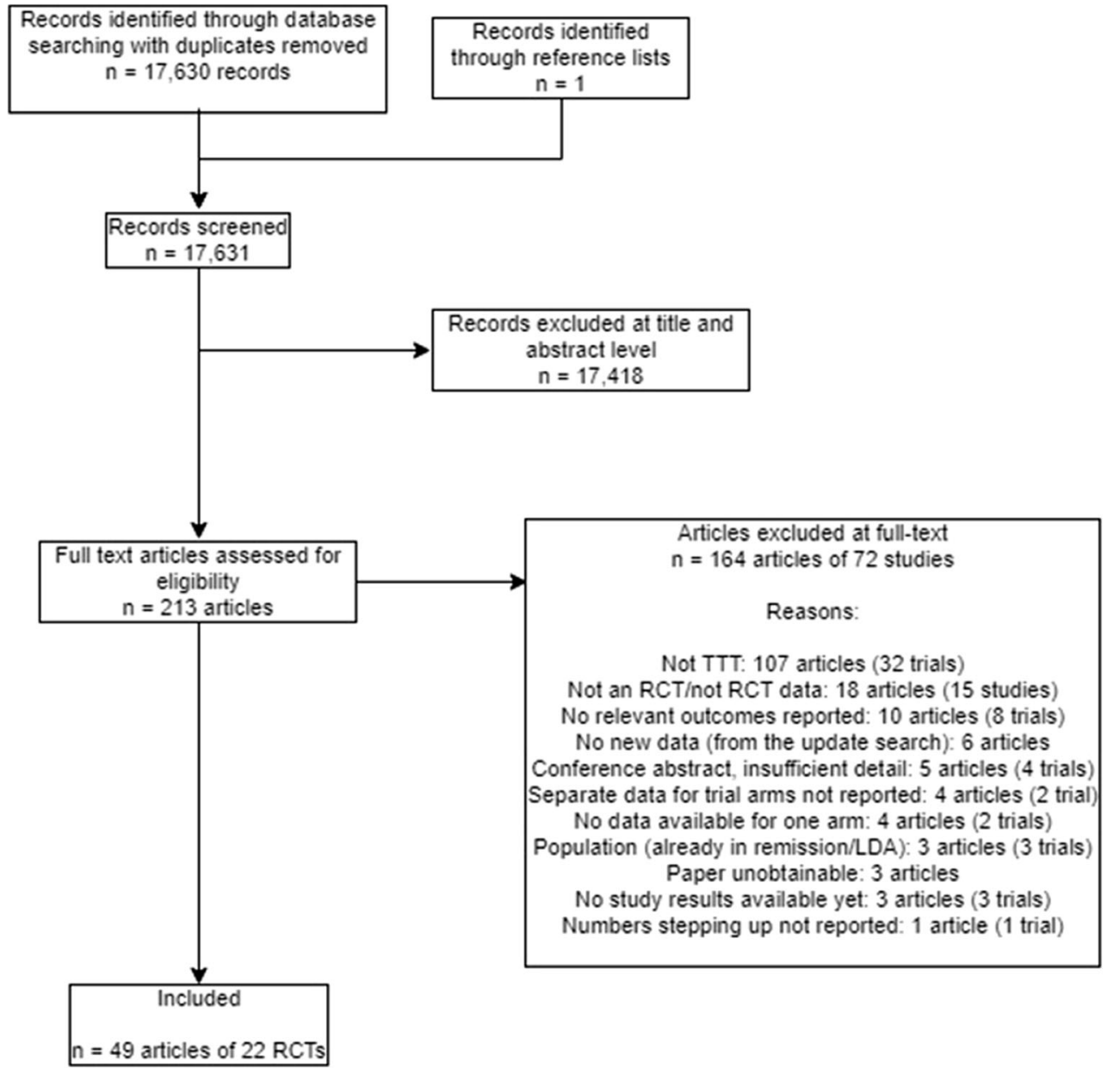

and established RA, 18-month treatment) reported the largest difference (intensive treatment $65 \%$, conventional treatment $16 \%, p<0.001$ ). The T-4 trial [24] (four groups, early RA, 12 -month treatment) reported a significant difference with DAS28-driven care compared with conventional treatment ( $38 \%$ vs $21 \%, p=0.05$ ). The Optimisation of Adalimumab trial $[26,41]$ (three groups, established RA, 18-month treatment) reported a significant difference between DAS28driven care and conventional treatment (38\% vs $16 \%, p=$ 0.027 ) in the ITT analysis but the completer analysis showed no significant difference. The STREAM trial [25] (two groups, early RA, 2-year treatment) reported more remissions with intensive than conventional treatment ( $66 \%$ vs $49 \%$ ); this difference was not significant.

The Fransen trial [27] (two groups, established RA, 6month treatment) only reported LDA; significantly more patients achieved LDA with intensive than conventional treatment ( $31 \%$ vs $16 \%, p=0.028)$. Similarly, the Bergsten trial [28] reported a greater proportion of patients achieved LDA with intensive (48\%) than conventional treatment $(24 \%)$. The van Hulst trial [22] (two groups, early and established RA, 18month treatment) reported more EULAR good responders (which includes LDA) with intensive (22\%) than conventional treatment (18\%) (significance unreported). In the Harrold trial [29], a similar proportion of patients achieved LDA with intensive (57\%) and conventional treatment (55\%).

\section{Comparison of Treatment Protocols}

All seven trials reported remissions [30-36]. Two trials involving conventionally treated controls reported significantly more remissions with intensive treatments. The U-Act-Early trial [36] (three groups, early RA, 24-month treatment) reported significantly more remissions with tocilizimab and methotrexate $(86 \%)$ than methotrexate monotherapy $(44 \%, p<$ 0.001). The FIN-RACo trial [33] (two groups, early RA, 24month treatment) reported $37 \%$ remissions with intensive combinations and $18 \%$ remissions with monotherapy ( $p=$ 0.003).

Five trials compared different intensive treatment regimens. They comprised the BeSt trial [30, 42] (four groups, early RA, 12-month treatment), the CareRA trial [43, 44] (five groups, early RA, 24-month treatment), the COBRA-light trial [45] (two groups, early RA, 12-month treatment), the Saunders trial [34] (two groups, early RA, 12-month treatment) and the TEAR trial [35] (four groups, early RA, 24- 


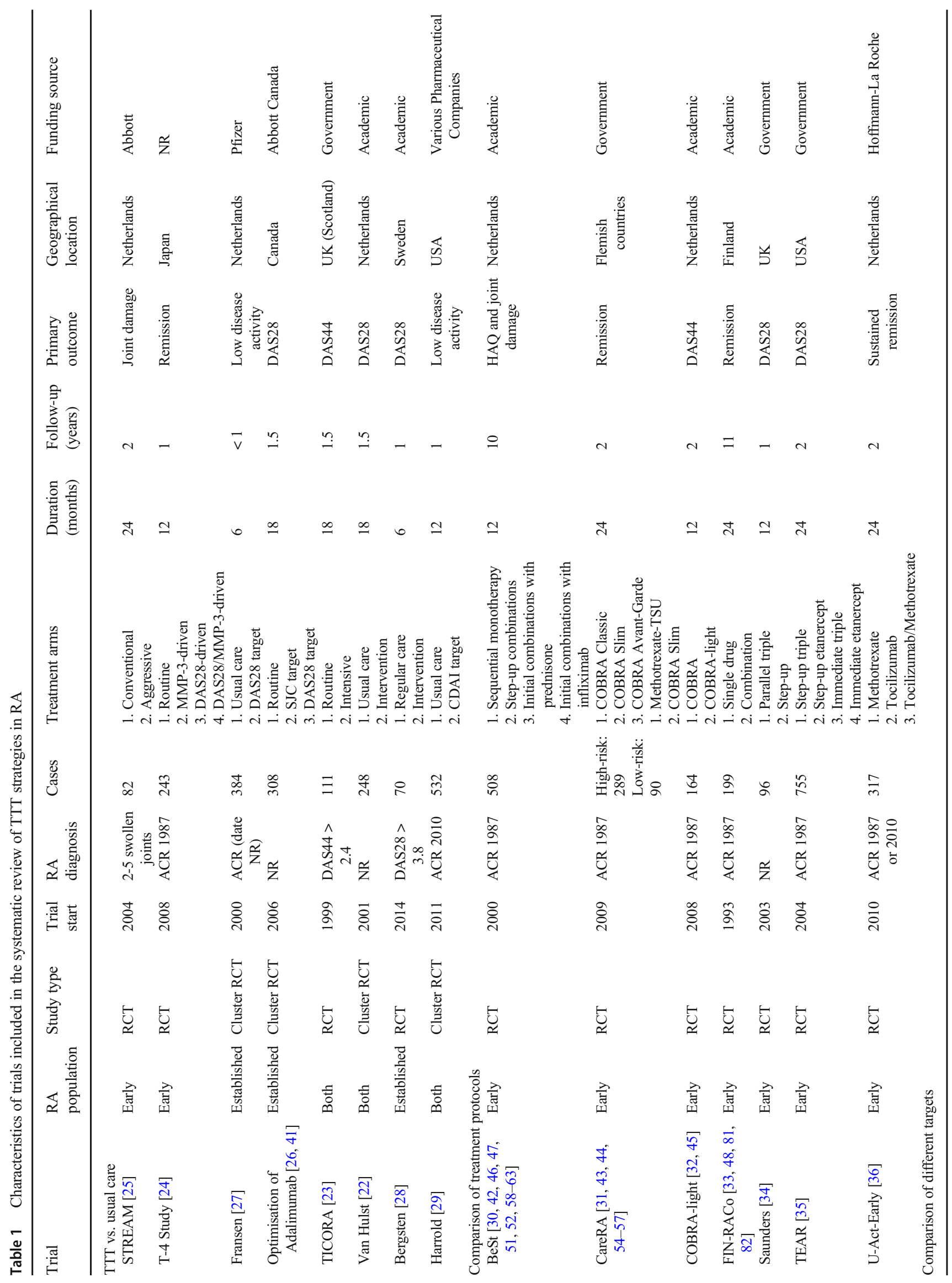




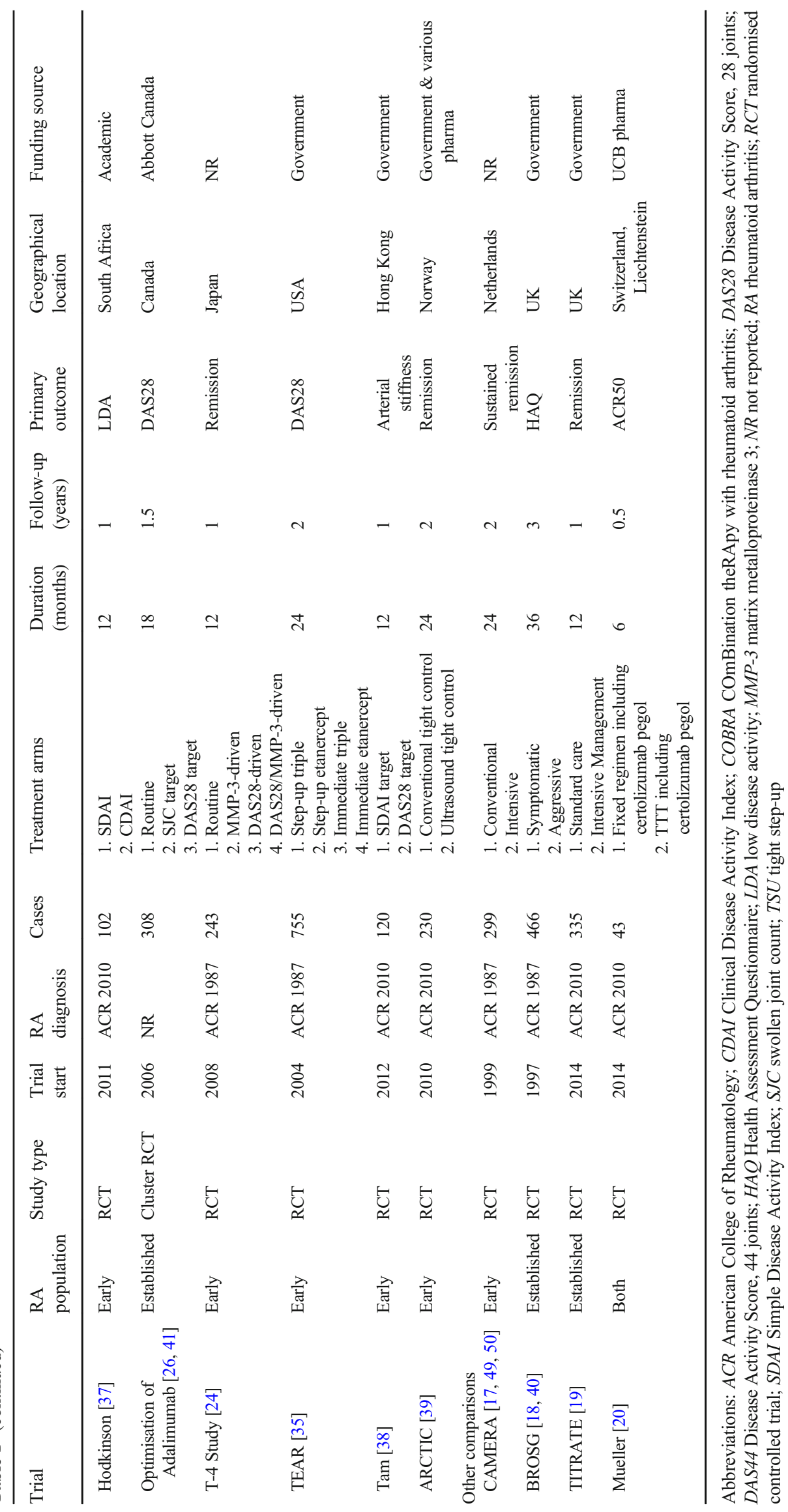




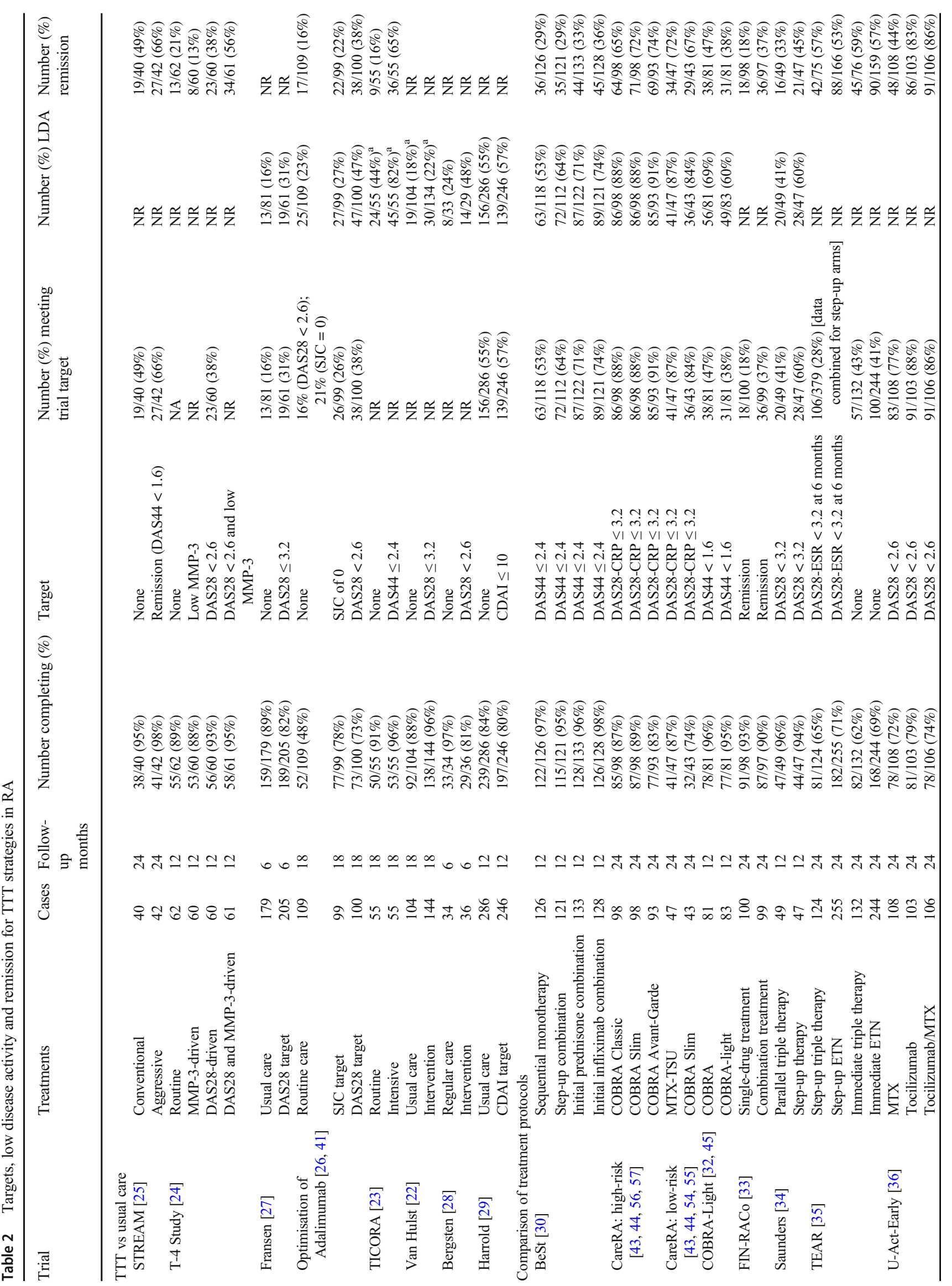




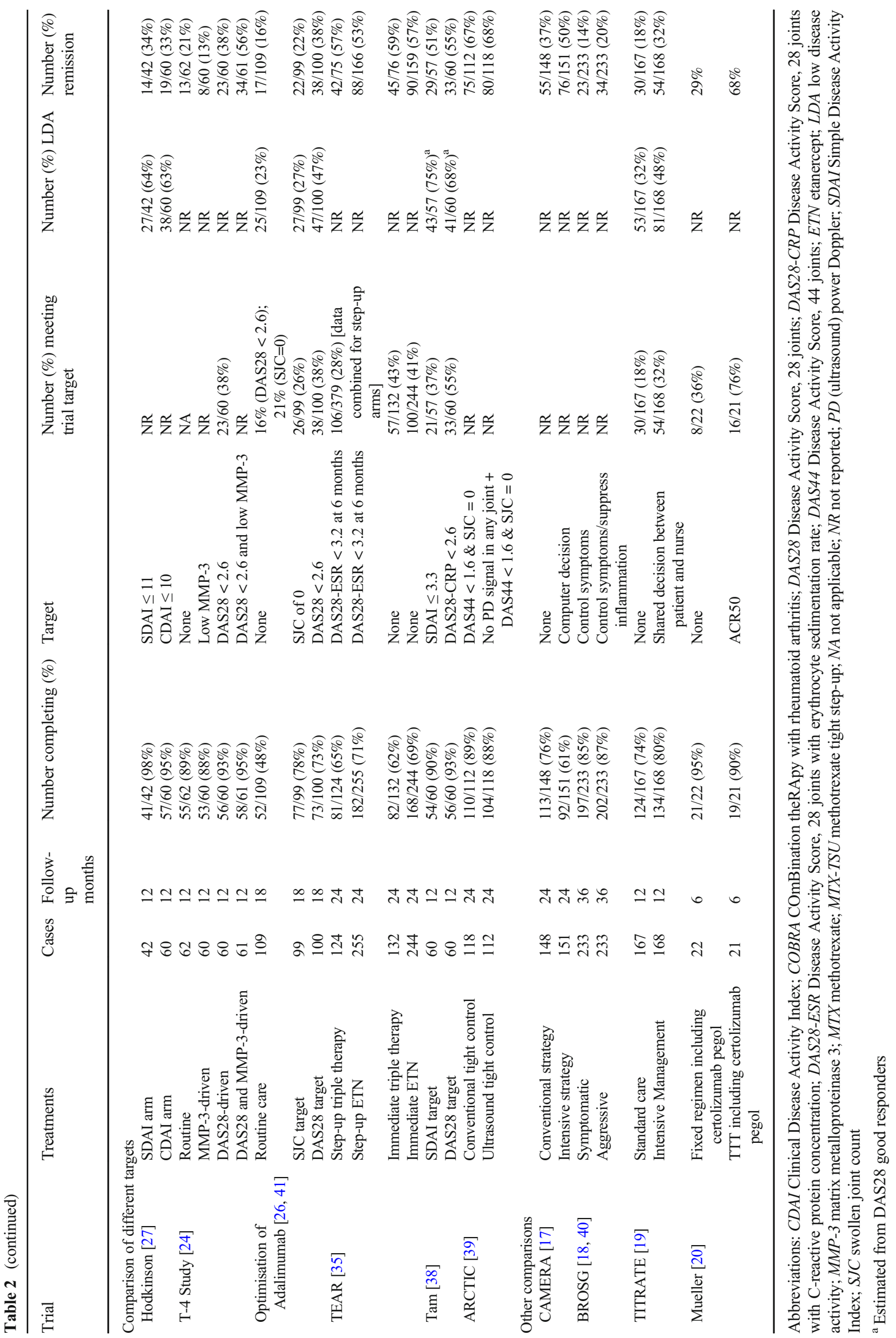



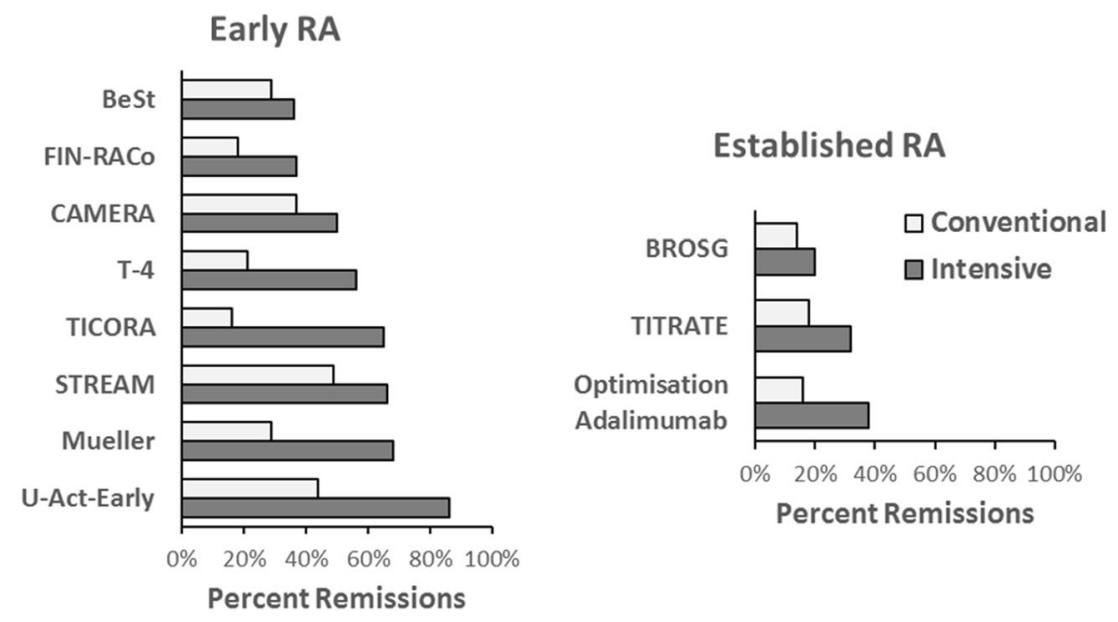

Fig. 2 Reported remissions at trial endpoints for TTT strategies vs standard care in rheumatoid arthritis RA rheumatoid arthritis, TTT treat-to-target

month treatment). There were no significant differences in remissions between comparable groups in these trials.

Longer-term outcomes were reported for the BeSt and Fin-RACo trials (Table 3). In the BeSt trial [46, 47], there were similar remission rates in the four arms over 10-year follow-up. In the FIN-RACo trial [48] at 11 years, patients receiving initial combination therapy had significantly more remissions than with monotherapy (37\% vs $19 \%)$, although there were no differences between groups at 5 years $(29 \%$ vs $22 \%)$.

\section{Different Targets and Other Comparisons}

The 10 trials reporting different targets and other comparisons all reported remissions. Three of the four trials involving conventionally treated controls reported more remissions with intensive treatments. The CAMERA trial [17, 49, 50] (two groups, early RA, 2-year treatment) reported significantly more remissions with intensive than conventional treatment (50\% vs 37\%, $p=0.03$ ). The BROSG trial [18] (two groups, established RA, 3-year treatment) also reported more remissions with intensive than conventional treatment $(20 \%$ vs
14\%); this difference was not significant. Likewise, the TITRATE trial [19] (two groups, established RA, 1-year treatment) reported significantly more remissions with intensive than conventional treatment ( $32 \%$ vs $18 \%$ ). The Mueller trial [20] compared a fixed regimen using certolizumab pegol with a TTT regimen using certolizumab pegol, and similarly reported significantly more remissions with more intensive treatment (68\% vs $29 \%$ ).

Four trials compared different treatment targets. The Hodkinson trial [37] (two groups, early RA, 12-month treatment) compared Clinical Disease Activity Index (CDAI) and Simple Disease Activity Index (SDAI) targets. The Tam trial [38] (two groups, early RA, 12-month treatment) compared SDAI and DAS28 remission targets. The ARCTIC trial [39] (two groups, early RA, 24-month treatment) compared a clinical target of DAS remission and no swollen joints with an ultrasound target of no power Doppler signal plus DAS remission and no swollen joints. The TEAR trial [35] (four groups, early RA, 24-month treatment) compared immediate treatment and step-up treatment to target LDA. All four trials reported no significant difference between groups.

Table 3 Long-term outcome in FIN-RACo and BeSt trials of TTT strategies in RA: remissions from 1 to 11 years

\begin{tabular}{|c|c|c|c|c|c|c|c|c|c|c|c|}
\hline \multirow[t]{2}{*}{ Trial } & \multirow[t]{2}{*}{ Treatments } & \multicolumn{10}{|l|}{ Years } \\
\hline & & \multicolumn{3}{|l|}{2} & \multicolumn{3}{|l|}{5} & \multicolumn{4}{|l|}{11} \\
\hline \multirow[t]{3}{*}{ FIN-RACo [48] } & Single-drug treatment & $18 \%$ & & & $22 \%$ & & & $19 \%$ & & & \\
\hline & Combination treatment & $37 \%$ & & & $29 \%$ & & & $37 \%$ & & & \\
\hline & & 1 & 2 & 3 & 4 & 5 & 6 & 7 & 8 & 9 & 10 \\
\hline \multirow[t]{4}{*}{ BeSt [42] } & Sequential monotherapy & $29 \%$ & $46 \%$ & $48 \%$ & $50 \%$ & $41 \%$ & $49 \%$ & $49 \%$ & $50 \%$ & $56 \%$ & $50 \%$ \\
\hline & Step-up combination & $29 \%$ & $38 \%$ & $39 \%$ & $40 \%$ & $45 \%$ & $50 \%$ & $40 \%$ & $56 \%$ & $47 \%$ & $46 \%$ \\
\hline & Initial prednisone combination & $33 \%$ & $42 \%$ & $40 \%$ & $39 \%$ & $42 \%$ & $51 \%$ & $53 \%$ & $57 \%$ & $56 \%$ & $57 \%$ \\
\hline & Initial infliximab combination & $36 \%$ & $41 \%$ & $48 \%$ & $41 \%$ & $51 \%$ & $55 \%$ & $45 \%$ & $47 \%$ & $46 \%$ & $56 \%$ \\
\hline
\end{tabular}

$R A$ rheumatoid arthritis; TTT treat-to-target 
Two TTT versus conventional treatment trials (T-4 and Optimisation of Adalimumab) also compared different treatment targets. In the T-4 trial [24], matrix metallopeptidase-3 (MMP-3)-guided treatment appeared less effective than DAS28-guided treatment. In the Optimisation of Adalimumab trial, [26, 41] swollen joint count (SJC)-guided treatment appeared less effective than DAS28-guided treatment, although this was not statistically significant.

\section{Disease Duration}

Thirteen trials studied early RA: five compared intensive management regimens with standard care and showed significantly more patients achieved remissions or LDA states with intensive management (T-4 [24], BeSt [30, 51], FIN-RACo [33], U-Act-Early [36], CAMERA [17, 49, 50]); one trial showed more remission with intensive treatment but the difference was not significant (STREAM [25]). Another seven early RA trials compared different intensive treatment regimens and showed comparable benefits (CareRA [43], COBRA-Light [32, 45], Saunders [34], Hodkinson [37], TEAR [35], Tam [38], ARCTIC [39]).

Five trials studied established RA: four compared intensive management regimens with standard care and showed significantly more patients achieved remissions or LDA states with intensive management (Fransen [27], Optimisation of Adalimumab [26, 41], Bergsten [28], TITRATE [19]); one trial found more remission with intensive treatment but the difference was not significant (BROSG [18]).

Four trials studied mixed populations of early and established RA: two trials showed significantly more remissions with intensive treatment than standard care (TICORA [23], Mueller [20]); the other two trials showed no significant impact of intensive treatment on LDA states (van Hulst [22], Harrold [29]).

\section{Adverse Events}

Five trials did not report harms (Fransen [27] van Hulst [22], BROSG [40], Hodkinson [37], Harrold [29]). Seventeen trials variously reported deaths, serious adverse events and withdrawals for adverse events (Table 4).

Deaths were reported in 13 trials: there were no deaths in five trials (U-Act-Early [36], STREAM [25], Mueller [20], Bergsten [28] and Tam [38]) and 29 deaths in the other eight trials (BeSt [51, 52], TEAR [35], Saunders [34] T-4 [24], TICORA [23], CareRA [44], TITRATE [19] and ARCTIC [39]). There were four deaths in three standard care arms and 13 deaths in 16 intensive treatment arms in which patients received a range of intensive treatments.

Serious adverse events were reported in 13 trials; all found some serious adverse events (TEAR [35], BeSt [30, 52], CareRA [44], COBRA-light [45], FIN-RACo [33], U-Act-
Early [36], STREAM [25], T-4 [24], TITRATE [19], Mueller [20], Tam [38] and ARCTIC [39]). 397/3368 (12\%) patients had a serious event: $346 / 2767$ (13\%) receiving intensive management and 51/614 $(8 \%)$ receiving standard care. Serious adverse event rates varied substantially across trials: they were greatest in the 24-month U-Act-Early trial (49/317, $15 \%)$ [36] and least in the 6-month T-4 trial [24] (5/243, 2\%).

Eleven trials reported withdrawals due to adverse events. No patients withdrew in three trials (STREAM [25], TICORA [23], Bergsten [28] and TITRATE [19]). In seven trials (TEAR [35], U-Act-Early [36], CAMERA [17], T-4 [24], Optimisation of Adalimumab [26], COBRA-light [32] and ARCTIC [39]), withdrawal rates varied substantially; they were highest in the CAMERA trial $(38 / 299,13 \%)$ [50]. In the CareRA trial [44], none of the low-risk patients withdrew from the trial; however, various numbers of patients withdrew from the three high-risk arms. There were 51/807 (6\%) withdrawals in seven standard care arms and 239/3009 (8\%) in 30 intensive treatment arms.

\section{Cost-Effectiveness}

The heterogeneity of data in the economic literature prohibited the construction of a single economic model that simultaneously compared all identified treatment strategies. Instead, each study considered in the clinical effectiveness section was evaluated separately. In some cases, a measure of the costeffectiveness was presented in the paper and could be extracted; in others, sufficient data was presented to allow a measure of incremental cost-effectiveness ratio (ICER), such as the incremental cost per additional patient in remission, to be estimated assuming annual typical costs of biologic therapy of $£ 9200$ per annum, and for simplicity assuming no costs for csDMARDs or for RA-related hospitalisations bar rheumatology visits, which were each assumed to cost $£ 128$ [7]. The analyses undertaken were in line with recommendations from NICE, which has a direct medical cost and personal social services perspective [65]. Further details are provided in Wailoo et al. [14]. For jurisdictions that do consider indirect costs, such as lost productivity and costs falling upon the individual, the ICERs would become more favourable to more efficacious treatment regimens.

In nine $[25,26,28,29,34,37,38,41,43,44,53-57]$ of the 22 studies, there was insufficient evidence to make any clear conclusion regarding incremental cost-effectiveness. Further details are provided in Wailoo et al. [14].

The 13 remaining studies $[17,22-24,27,30,33,35,36$, 40] contained sufficient evidence to allow a measure of ICER to be estimated with some degree of confidence. In six studies, one intervention was estimated to dominate another (greater health-related benefits at reduced costs). From the data contained in FIN-RACo [33], it was estimated combination drug therapy likely dominates single-drug therapy. From the 
Table 4 Numbers of patients with adverse events in trials of treat-to-target strategies in rheumatoid arthritis

\begin{tabular}{|c|c|c|c|c|c|c|}
\hline \multirow[t]{2}{*}{ Trial } & \multirow[t]{2}{*}{ Treatments } & \multirow{2}{*}{$\begin{array}{l}\text { Follow-up } \\
\text { (months) }\end{array}$} & \multirow[t]{2}{*}{ Cases } & \multicolumn{3}{|c|}{ Adverse events } \\
\hline & & & & Serious & Deaths & Withdrawal \\
\hline \multirow[t]{4}{*}{ TEAR [35] } & Step-up triple therapy & 24 & 124 & 16 & 0 & 4 \\
\hline & Step-up ETN & 24 & 255 & 32 & 2 & 9 \\
\hline & Immediate triple therapy & 24 & 132 & 18 & 1 & 7 \\
\hline & Immediate ETN & 24 & 244 & 35 & 1 & 12 \\
\hline \multirow[t]{3}{*}{ U-Act-Early [36] } & MTX & 24 & 108 & 13 & 0 & 8 \\
\hline & Tocilizumab & 24 & 103 & 19 & 0 & 10 \\
\hline & Tocilizumab/MTX & 24 & 106 & 17 & 0 & 9 \\
\hline \multirow[t]{4}{*}{ BeSt [83] } & Sequential monotherapy & 24 & 126 & 21 & 3 & NR \\
\hline & Step-up combination & 24 & 121 & 19 & 3 & NR \\
\hline & Initial prednisone combination & 24 & 133 & 28 & 2 & NR \\
\hline & Initial infliximab combination & 24 & 128 & 14 & 4 & NR \\
\hline \multirow[t]{4}{*}{ BeSt [51] } & Sequential monotherapy & 120 & 126 & NR & NR & 16 \\
\hline & Step-up combination & 120 & 121 & NR & NR & 15 \\
\hline & Initial prednisone combination & 120 & 133 & NR & NR & 21 \\
\hline & Initial infliximab combination & 120 & 128 & NR & NR & 20 \\
\hline \multirow[t]{3}{*}{ CareRA: high-risk $[43,44,57]$} & COBRA Classic & 24 & 98 & 21 & 1 & $12^{\mathrm{a}}$ \\
\hline & COBRA Slim & 24 & 98 & 22 & 1 & $6^{\mathrm{a}}$ \\
\hline & COBRA Avant-Garde & 24 & 93 & 16 & 0 & $13^{\mathrm{a}}$ \\
\hline \multirow[t]{2}{*}{ CareRA: low-risk $[43,44,55]$} & MTX-TSU & 24 & 47 & 7 & 0 & $0^{\mathrm{a}}$ \\
\hline & COBRA Slim & 24 & 43 & 9 & 0 & $0^{\mathrm{a}}$ \\
\hline \multirow[t]{2}{*}{ CAMERA [50] } & Conventional strategy & 24 & 140 & NR & NR & 11 \\
\hline & Intensive strategy & 24 & 149 & NR & NR & 27 \\
\hline \multirow[t]{4}{*}{ T-4 Study [24] } & Routine & 12 & 62 & 1 & 0 & 6 \\
\hline & MMP-3-driven & 12 & 60 & 3 & 2 & 6 \\
\hline & DAS28-driven & 12 & 60 & 0 & 0 & 3 \\
\hline & DAS28 and MMP-3-driven & 12 & 61 & 1 & 0 & 2 \\
\hline \multirow[t]{2}{*}{ Hodkinson [37] } & SDAI target & 12 & NR & NR & NR & NR \\
\hline & CDAI target & 12 & NR & NR & NR & NR \\
\hline \multirow[t]{2}{*}{ Fransen [27] } & Usual care & 6 & NR & NR & NR & NR \\
\hline & DAS28 target & 6 & NR & NR & NR & NR \\
\hline \multirow{3}{*}{$\begin{array}{l}\text { Optimisation of } \\
\text { Adalimumab }[26,41]\end{array}$} & Routine care & 18 & 109 & NR & NR & 10 \\
\hline & SJC target & 18 & 99 & NR & NR & 4 \\
\hline & DAS28 target & 18 & 100 & NR & NR & 12 \\
\hline \multirow[t]{2}{*}{ TICORA [23] } & Routine & 18 & 55 & NR & 3 & 0 \\
\hline & Intensive & 18 & 55 & NR & 1 & 0 \\
\hline \multirow[t]{2}{*}{ Van Hulst [22] } & Usual care & 18 & NR & NR & NR & NR \\
\hline & Intervention & 18 & NR & NR & NR & NR \\
\hline \multirow[t]{2}{*}{ STREAM [25] } & Conventional & 24 & 40 & 3 & 0 & 0 \\
\hline & Aggressive & 24 & 42 & 5 & 0 & 0 \\
\hline \multirow[t]{2}{*}{ COBRA-Light [32] } & COBRA & 12 & 81 & 9 & NR & 1 \\
\hline & COBRA-light & 12 & 83 & 16 & NR & 1 \\
\hline \multirow[t]{2}{*}{ FIN-RACo [33] } & Single-drug treatment & 24 & 98 & 3 & NR & NR \\
\hline & Combination treatment & 24 & 97 & 5 & NR & NR \\
\hline Saunders [34] & Parallel triple therapy & 12 & NR & NR & 1 & 15 \\
\hline & Step-up therapy & 12 & NR & NR & 0 & 18 \\
\hline TITRATE [19] & Standard Care & 12 & 167 & 10 & 1 & 0 \\
\hline & Intensive Management & 12 & 168 & 12 & 2 & 0 \\
\hline
\end{tabular}


Table 4 (continued)

\begin{tabular}{|c|c|c|c|c|c|c|}
\hline \multirow[t]{2}{*}{ Trial } & \multirow[t]{2}{*}{ Treatments } & \multirow{2}{*}{$\begin{array}{l}\text { Follow-up } \\
\text { (months) }\end{array}$} & \multirow[t]{2}{*}{ Cases } & \multicolumn{3}{|c|}{ Adverse events } \\
\hline & & & & Serious & Deaths & Withdrawal \\
\hline \multirow[t]{2}{*}{ Mueller [20] } & $\begin{array}{l}\text { Fixed regimen including } \\
\text { Certolizumab Pegol }\end{array}$ & 6 & 22 & 1 & 0 & NR \\
\hline & $\begin{array}{l}\text { TTT including Certolizumab } \\
\text { Pegol }\end{array}$ & 6 & 21 & 2 & 0 & NR \\
\hline \multirow[t]{2}{*}{ Bergsten [28] } & Regular care & 6 & NR & NR & 0 & 0 \\
\hline & Intervention & 6 & NR & NR & 0 & 0 \\
\hline \multirow[t]{2}{*}{ Harrold [29] } & Usual care & 12 & NR & NR & NR & NR \\
\hline & CDAI target & 12 & NR & NR & NR & NR \\
\hline \multirow[t]{2}{*}{ Tam [38] } & SDAI target & 12 & 57 & 3 & 0 & NR \\
\hline & DAS28 target & 12 & 60 & 3 & 0 & NR \\
\hline \multirow[t]{2}{*}{ ARCTIC [39] } & Conventional tight control & 24 & 112 & 7 & 0 & 5 \\
\hline & Ultrasound tight control & 24 & 118 & 6 & 1 & 7 \\
\hline
\end{tabular}

Abbreviations: CDAI Clinical Disease Activity Index; COBRA COmBination theRApy with rheumatoid arthritis; DAS-28 Disease Activity Score, 28 joints; ETN etanercept; $M M P$-3 matrix metalloproteinase 3; MTX methotrexate; MTX-TSU methotrexate tight step-up; NR not reported; SDAI Simple Disease Activity Index; SJC swollen joint count

${ }^{\mathrm{a}} \mathrm{AE}$ causing treatment stop

evidence in the TICORA trial [23], it was estimated intensive care dominates routine care. According to the data contained in the Fransen trial [27] systematic monitoring dominates usual care. Data from the van Hulst trial [22] implied that usual care dominated a nurse-led approach. Mueller at al. [20] showed that on top of a backbone of certolizumab pegol treatment, a TTT approach for csDMARD treatment had significantly better clinical outcomes than fixed csDMARD treatment. Finally, data from ARCTIC [39] showed that an ultrasound-guided tight control strategy was associated with a statistically significant increase in bDMARD use, but that there was no statistically significant difference in outcome measures.

The authors calculated ICERs for the remaining seven studies. For reference, NICE are unlikely to fund interventions that have a cost per QALY greater than $£ 30,000$ [64]. In TITRATE, Scott et al. [19] explicitly calculated a cost per QALY which was $£ 43,972$ using a medical and personal social services perspective. This value became $£ 29,363$ when indirect costs and personal costs were included, although these aspects are not included in the NICE reference case. Using data contained in the BROSG trial [40], an ICER for shared care versus hospital treatment of $£ 1517$ per QALY (£7571 when baseline utility differences were considered) was estimated. From evidence in CAMERA [17], it was estimated intensive therapy would be cost-effective when compared with conventional therapy, due to an estimated incremental cost of $£ 110$ per patient in remission. Using data in the T-4 trial [24], basing treatment decisions on DAS28 in combination with MMP-3 was estimated to cost less than $£ 170$ per patient in remission compared with treatments driven by
DAS28 alone, MMP-3 alone and routine care, indicating that a combination protocol would be cost-effective [24]. Evidence from the TEAR trial [35] indicates the additional costs associated with the immediate use of etanercept or the use of etanercept before triple csDMARD therapy would not be justified by the gain in health-related benefits. The higher expense associated with initial combination therapy with infliximab in the BeSt trial [30, 42, 46, 47, 51, 52, 58-63] does not appear to be justified due to the lack of any significant gain in health-related benefits compared with initial combination therapy with prednisone. The evidence contained in the U-Act-Early trial [36] indicates that a significantly higher percentage of people treated with tocilizumab, as monotherapy or in combination with methotrexate, achieved sustained remission than did methotrexate monotherapy. However, since tocilizumab is a bDMARD, it would be associated with markedly higher costs compared with the costs associated with methotrexate, a csDMARD, on which $44 \%$ of patients achieved a sustained remission. The estimated ICER was a cost of $£ 41,818$ per additional sustained remission for early tocilizumab treatment.

\section{Discussion}

Our systematic review of 22 different trials of TTT strategies in RA, which enrolled 5990 RA patients, provides robust evidence supporting their use. Firstly, TTT strategies were effective overall; more patients achieved remission or LDA with TTT approaches than with standard care. Secondly, there was no evidence TTT strategies increased harms compared with 
usual care. Finally, TTT strategies were largely cost-effective. The trials employed a wide range of different TTT strategies and there was no evidence to favour any particular strategy; several different approaches were equally effective. Although TTT strategies were effective in a broad range of RA patients, the impact of this approach was most marked in early RA. Sixteen trials had high risk of bias, five unclear risk and one low risk of bias.

There are several challenges evaluating TTT strategies. Firstly, the trials involved a broad range of different treatment approaches in diverse patient groups using varying target definitions and durations. The extent of this diversity precluded undertaking a meta-analysis. Secondly, several TTT components, including treatment intensities, treatment targets, frequent review and personalised care, may all account for its benefits. Thirdly, although remission is the preferred target, LDA is also relevant and is achieved by more patients. The frequency of remission with TTT strategies also varied substantially. In two trials-U-Act-Early and TICORA - most intensively-treated patients achieved remission, but these findings were exceptional and lower numbers of patients achieved remission in the majority of trials. Finally, long-term follow-up of two trials-BeSt and Fin-RACo-gave diverse findings. In BeSt, all treatment groups had similar long-term outcomes. In Fin-RACo, initial intensive treatment maintained its benefit. BeSt was undertaken in the biologic era while Fin-RACo predated widespread biologic use; these follow-up findings may reflect post-trial treatment differences rather than the impact of one type of TTT strategy.

Evidence that TTT approaches were cost-effective was strongest in early RA. Conclusions about cost-effectiveness could be made in thirteen trials. Estimates from these studies indicated TTT was usually cost-effective; the exception was if bDMARDs were used as the initial treatment. Initial intensive treatment using csDMARDs appeared most cost-effective. Health economic evaluations of the TEAR trial provided particularly strong evidence in favour of the cost-effectiveness of initial treatment with csDMARD therapy and only using bDMARDs when patients do not respond [65].

TTT strategies have been followed for over 10 years [66] (Smolen, 2019). Their use is well established in RA and is supported by many clinical guidelines; our findings support these recommendations [67-70]. RA guidelines are cautious about using bDMARDs as first-line therapies and do not encourage this approach; our economic analyses suggest such caution is appropriate [67-70]. Despite the strength of support for TTT strategies, there are many challenges implementing such approaches in routine practice. Not all specialists accept the guidance, and there are wide variations in views on treatment and the organisation of care approaches $[71,72]$. In many centres, disease activity is not routinely measured using quantitative approaches [73], and not all centres have dedicated clinics for RA patients in general and early RA in particular. A range of additional factors influence TTT implementation in routine practice. The frequency of visits and the value of a 3-month assessment are important considerations [74]. Patients' involvement in assessing their RA may have a crucial role using methods like the PatientReported Outcomes Measurement Information System [75]. There is also a role for training clinical staff in TTT methods [76], although the overall impact of training is uncertain [29].

Strengths of our systematic review include robust searching of several databases and secondary sources, following PRISMA principles, undertaking independent study selection and data extraction and assessing the quality of included studies. Heterogeneity across studies meant we were unable to undertake pair-wise meta-analysis, with limited assessment of publication bias. Our conclusions also have several limitations. Firstly, there were quality concerns about some TTT trials. Risk of bias was high in 12 conventional and four cluster trials and was only low in TICORA [23]. Secondly, some trials had small sample sizes and uneven baseline variable distribution, exemplified by the STREAM trial [25]. Thirdly, each comparison and population group involved relatively few trials. Fourthly, there was heterogeneity in targets, treatment protocols, contact frequencies, outcomes and follow-up time points. Fifthly, trials such as TEAR, treatment acceleration and escalation in different arms complicated defining the comparative effectiveness of the various strategies used. Sixthly, DAS28 $<2.6$ remissions do not preclude ongoing disease activity and radiological progression, although the ARCTIC trial [39] found no difference in remission rates between a conventional tight control strategy aiming for clinical remission and an ultrasound remission-guided strategy. Finally, there are insufficient trials to be certain TTT is cost-effective among established RA patients.

Five previous systematic reviews have combined data from RCTs and non-randomised studies; two $[9,11]$ informed international recommendations $[8,10]$ concluding TTT was more effective than usual care. Assessments by Jurgens et al. [77], Schipper et al. [78] and Bakker et al. [79] highlighted the benefits of TTT compared with usual care. Knevel et al. [80] found no evidence to recommend one particular target over others in a synthesis of trials and non-randomised studies, concluding evidence supporting TTT was limited to early RA. Our systematic review had more stringent inclusion criteria, only examining RCTs to minimise bias, and included health economic assessments.

We conclude that TTT strategies are effect, safe and often cost-effective. Their impact is most marked in early RA, where there is strong evidence of increased remissions, and in patient groups containing both early and established RA. In 
established RA TTT strategies increase LDA but their impact on remissions is less certain. The trials assessed a range of different TTT strategies and there is no reason to prefer any particular strategy.

Supplementary Information The online version contains supplementary material available at https://doi.org/10.1007/s42399-021-00727-4.

Authors' Contributions Allan Wailoo oversaw and contributed to all aspects of the project. Naila Dracup devised and ran the search strategies. Emma S. Hock, Marrissa Martyn-St James and Emma L. Simpson undertook the literature review relating to clinical effectiveness, detailed the identified studies and provided the summary of evidence found. Matt Stevenson and Andrew Rawdin undertook the review of cost-effectiveness papers and produced the estimates of cost-effectiveness related to each study identified in the clinical effectiveness review. David L. Scott and Adam Young provided clinical advice to the project and commented on specific aspects of the clinical evidence. The first draft of the manuscript was written by Emma S. Hock, and all authors edited and commented on previous versions of the manuscript. All authors read and approved the final manuscript.

Funding This review formed part of a review of treat-to-target strategies in rheumatoid arthritis, which was commissioned by the National Institute for Health Research (NIHR) HTA Programme as project number 14/17/ 01 and also independent research funded by the NIHR as one of its Programme Grants For Applied Research (Grant Reference Number: RP-PG-0610-10066). The views expressed are those of the authors and not necessarily those of the NHS, the NIHR or the Department of Health.

Data Availability The data is collected from the studies published online, publicly available, and specific details related to data and/or analysis will be made available upon request.

\section{Compliance with Ethical Standards}

Conflict of Interest David L. Scott has declared personal fees for advisory board contributions from Baxalta, Novartis UK, and AbbVie, outside the submitted work. No other authors have declared any competing interests.

Ethical Approval This article is a literature review and did not involve any primary research with humans or animals.

Consent to Participate This article is a literature review and did not involve any primary research with humans or animals.

Consent for Publication Not applicable.

\section{Code Availability Not applicable.}

Open Access This article is licensed under a Creative Commons Attribution 4.0 International License, which permits use, sharing, adaptation, distribution and reproduction in any medium or format, as long as you give appropriate credit to the original author(s) and the source, provide a link to the Creative Commons licence, and indicate if changes were made. The images or other third party material in this article are included in the article's Creative Commons licence, unless indicated otherwise in a credit line to the material. If material is not included in the article's Creative Commons licence and your intended use is not permitted by statutory regulation or exceeds the permitted use, you will need to obtain permission directly from the copyright holder. To view a copy of this licence, visit http://creativecommons.org/licenses/by/4.0/.

\section{References}

1. Smolen JS, Aletaha D, McInnes IB. Rheumatoid arthritis. Lancet. 2016;388:2023-38.

2. Scott DL, Wolfe F, Huizinga TWJ. Rheumatoid arthritis. Lancet. 2010;376:1094-108.

3. Pincus T, Fuchs HA, Callahan LF, Nance EP, Kaye JJ. Early radiographic joint space narrowing and erosion and later malalignment in rheumatoid arthritis: a longitudinal analysis. J Rheumatol. 1998;25:636-40.

4. Drossaers-Bakker KW, Kroon HM, Zwinderman AH, Breedveld FC, Hazes JM. Radiographic damage of large joints in long-term rheumatoid arthritis and its relation to function. Rheumatology. 2000;39:998-1003.

5. Minichiello E, Semerano L, Boissier MC. Time trends in the incidence, prevalence, and severity of rheumatoid arthritis: a systematic literature review. Joint Bone Spine. 2016;83:625-30.

6. Smolen JS, Landewé RBM, Bijlsma JWJ, Burmester GR, Dougados M, Kerschbaumer A, et al. EULAR recommendations for the management of rheumatoid arthritis with synthetic and biological disease-modifying antirheumatic drugs: 2019 update. Ann Rheum Dis. 2020;79:685-99.

7. Stevenson M, Archer R, Tosh J, Simpson E, Everson-Hock E, Stevens J, et al. Adalimumab, etanercept, infliximab, certolizumab pegol, golimumab, tocilizumab and abatacept for the treatment of rheumatoid arthritis not previously treated with disease-modifying antirheumatic drugs and after the failure of conventional diseasemodifying antirheumatic drugs only: systematic review and economic evaluation. Health Technol Assess. 2016;20:1-610.

8. Smolen JS, Aletaha D, Bijlsma JW, Breedveld FC, Boumpas D, Burmester G, et al. Treating rheumatoid arthritis to target: recommendations of an international task force. Ann Rheum Dis. 2010;69:631-7.

9. Schoels M, Knevel R, Aletaha D, Bijlsma JW, Breedveld FC, Boumpas DT, et al. Evidence for treating rheumatoid arthritis to target: results of a systematic literature search. Ann Rheum Dis. 2010;69:638-43.

10. Smolen JS, Breedveld FC, Burmester GR, Bykerk V, Dougados M, Emery P, et al. Treating rheumatoid arthritis to target: 2014 update of the recommendations of an international task force. Ann Rheum Dis. 2016;75:3-15.

11. Stoffer MA, Schoels MM, Smolen JS, Aletaha D, Breedveld FC, Burmester G, et al. Evidence for treating rheumatoid arthritis to target: results of a systematic literature search update. Ann Rheum Dis. 2016;75:16-22.

12. Goswami RP, Basu K, Das S, Mondal S, Ghosh P, Ghosh A. Evidence for treating rheumatoid arthritis to target: results of a systematic literature search update. Ann Rheum Dis. 2016;75:e35.

13. Vermeer M, Kievit W, Kuper HH, Braakman-Jansen LM, Bernelot Moens HJ, Zijlstra TR, et al. Treating to the target of remission in early rheumatoid arthritis is cost-effective: results of the DREAM registry. BMC Musculoskelet Disord. 2013;14:350.

14. Wailoo A, Hock ES, Stevenson M, Martyn-St James M, Rawdin A, Simpson E, et al. The clinical effectiveness and cost-effectiveness of treat-to-target strategies in rheumatoid arthritis: a systematic review and cost-effectiveness analysis. Health Technol Assess. 2017;21:1-258.

15. Higgins JPT, Altman DG, Sterne JAC. Chapter 8: Assessing risk of bias in included studies. In: Higgins JPT, Green S, editors. Cochrane Handbook for Systematic Reviews of Interventions Version 5.1.0. The Cochrane Collaboration. 2011. http://www. handbook.cochrane.org Accessed August 15, 2016.

16. Wright CC, Sim J. Intention-to-treat approach to data from randomized controlled trials: a sensitivity analysis. J Clin Epidemiol. 2003;56:833-42. 
17. Verstappen SM, Jacobs JW, Veen MJ, Heurkens AH, Schenk Y, ter Borg EJ, et al. Intensive treatment with methotrexate in early rheumatoid arthritis: aiming for remission. Computer Assisted Management in Early Rheumatoid Arthritis (CAMERA, an openlabel strategy trial). Ann Rheum Dis. 2007;66:1443-9.

18. Symmons D, Tricker K, Harrison M, Roberts C, Davis M, Dawes P, et al. Patients with stable long-standing rheumatoid arthritis continue to deteriorate despite intensified treatment with traditional disease modifying anti-rheumatic drugs - results of the British Rheumatoid Outcome Study Group randomized controlled clinical trial. Rheumatology. 2006;45:558-65.

19. Scott D, Ibrahim F, Hill H, Tom B, Prothero L, Baggott RR, et al. The clinical effectiveness of intensive management in moderate established rheumatoid arthritis: the TITRATE trial. Semin Arthritis Rheum. 2020;50:1182-90.

20. Mueller RB, Spaeth M, von Restorff C, Ackermann C, SchulzeKoops H, von Kempis J. Superiority of a treat-to-target strategy over conventional treatment with fixed csDMARD and corticosteroids: a multi-center randomized controlled trial in RA patients with an inadequate response to conventional synthetic DMARDs, and new therapy with Certolizumab pegol. J Clin Med. 2019;8:302.

21. Scott DL, Ibrahim F, Farewell V, O'Keeffe AG, Ma M, Walker D, et al. Randomised controlled trial of tumour necrosis factor inhibitors against combination intensive therapy with conventional disease-modifying antirheumatic drugs in established rheumatoid arthritis: the TACIT trial and associated systematic reviews. Health Technol Assess. 2014;18:1-164.

22. van Hulst LT, Creemers MC, Fransen J, Li LC, Grol R, Hulscher $\mathrm{ME}$, et al. How to improve DAS28 use in daily clinical practice? A pilot study of a nurse-led intervention. Rheumatol. 2010;49:741-8.

23. Grigor C, Capell H, Stirling A, McMahon AD, Lock P, Vallance R, et al. Effect of a treatment strategy of tight control for rheumatoid arthritis (the TICORA study): a single-blind randomised controlled trial. Lancet. 2004;364:263-9.

24. Urata Y, Uesato R, Tanaka D, Nakamura Y, Motomura S. Treating to target matrix metalloproteinase 3 normalisation together with disease activity score below 2.6 yields better effects than each alone in rheumatoid arthritis patients: T-4 Study. Ann Rheum Dis. 2012;71:534-40.

25. van Eijk IC, Nielen MM, van der Horst-Bruinsma I, Tijhuis GJ, Boers M, Dijkmans BA, et al. Aggressive therapy in patients with early arthritis results in similar outcome compared with conventional care: the STREAM randomized trial. Rheumatol. 2012;51:68694.

26. Pope JE, Haraoui B, Rampakakis E, Psaradellis E, Thorne C, Sampalis JS. Treating to a target in established active rheumatoid arthritis patients receiving a tumor necrosis factor inhibitor: results from a real-world cluster-randomized adalimumab trial. Arthritis Care Res. 2013;65:1401-9.

27. Fransen J, Moens HB, Speyer I, van Riel PL. Effectiveness of systematic monitoring of rheumatoid arthritis disease activity in daily practice: a multicentre, cluster randomised controlled trial. Ann Rheum Dis. 2005;64:1294-8.

28. Bergsten U, Almehed K, Baigi A, Jacobsson LT. A randomized study comparing regular care with a nurse-led clinic based on tight disease activity control and person-centred care in patients with rheumatoid arthritis with moderate/high disease activity: a 6month evaluation. Musculoskelet Care. 2019;17:215-25.

29. Harrold LR, Reed GW, John A, Barr CJ, Soe K, Magner R, et al. Cluster-randomized trial of a behavioral intervention to incorporate a treat-to-target approach to care of US patients with rheumatoid arthritis. Arthritis Care Res. 2018;70:379-87.

30. Goekoop-Ruiterman YP, de Vries-Bouwstra JK, Allaart CF, van Zeben D, Kerstens PJ, Hazes JM, et al. Clinical and radiographic outcomes of four different treatment strategies in patients with early rheumatoid arthritis (the BeSt study): a randomized, controlled trial. Arthritis Rheum. 2005;52:3381-90.

31. Verschueren P, Cock D, Corluy L, Joos R, Langenaken C, Taelman $\mathrm{V}$, et al. THU0137 Associated with a glucocorticoid bridging scheme, methotrexate is as effective alone as in combination with other DMARDs for early rheumatoid arthritis, with fewer reported side effects: 16 weeks remission induction data from the carera trial (abstract). Ann Rheum Dis. 2014;73:226.

32. den Uyl D, ter Wee M, Boers M, Kerstens P, Voskuyl A, Nurmohamed M, et al. A non-inferiority trial of an attenuated combination strategy ('COBRA-light') compared to the original COBRA strategy: clinical results after 26 weeks. Ann Rheum Dis. 2014;73:1071-8.

33. Mottonen T, Hannonen P, Leirisalo-Repo M, Nissila M, Kautiainen $\mathrm{H}$, Korpela M, et al. Comparison of combination therapy with single-drug therapy in early rheumatoid arthritis: a randomised trial. Lancet. 1999;353:1568-73.

34. Saunders SA, Capell HA, Stirling A, Vallance R, Kincaid W, McMahon AD, et al. Triple therapy in early active rheumatoid arthritis. Arthritis Rheum. 2008;58:1310-7.

35. Moreland LW, O'Dell JR, Paulus HE, Curtis JR, Bathon JM, St Clair EW, et al. A randomized comparative effectiveness study of oral triple therapy versus etanercept plus methotrexate in early aggressive rheumatoid arthritis the treatment of early aggressive rheumatoid arthritis trial. Arthritis Rheum. 2012;64:2824-35.

36. Bijlsma JW, Welsing PM, Woodworth TG, Middelink LM, PethoSchramm A, Bernasconi C, et al. Early rheumatoid arthritis treated with tocilizumab, methotrexate, or their combination (U-ActEarly): a multicentre, randomised, double-blind, double-dummy, strategy trial. Lancet. 2016;388:343-55.

37. Hodkinson B, Musenge E, Tikly M. Tight control of rheumatoid arthritis in a resource-constrained setting: a randomized controlled study comparing the clinical disease activity index and simplified disease activity index. Rheumatol. 2015;54:1033-8.

38. Tam LH, Shang Q, Li EK, Wong PC, Kwok KY, Kun EW, et al. Effect of treat-to-target strategies aiming at remission of arterial stiffness in early rheumatoid arthritis: a randomized controlled study. J Rheumatol. 2018;45:1229-39.

39. Haavardsholm EA, Aga AB, Olsen IC, Lillegraven S, Hammer HB, Uhlig $\mathrm{T}$, et al. Ultrasound in management of rheumatoid arthritis: ARCTIC randomised controlled strategy trial. BMJ. 2016;354: i4205.

40. Symmons D, Tricker K, Roberts C, Davies L, Dawes P, Scott DL. The British Rheumatoid Outcome Study Group (BROSG) randomised controlled trial to compare the effectiveness and costeffectiveness of aggressive versus symptomatic therapy in established rheumatoid arthritis. Health Technol Assess. 2005;9: $1-78$.

41. Pope JE, Thorne JC, Haraoui B, Sampalis J. Treating to target with TNFi in active established rheumatoid arthritis results in longer drug survival than routine care with TNFi: results from the optimization of Humira RCT. Arthritis Rheum Suppl. 2010;62(Suppl 10): 344.

42. Markusse IM, Akdemir G, Dirven L, Goekoop-Ruiterman YP, van Groenendael JH, Han KH, et al. Long-term outcomes of patients with recent-onset rheumatoid arthritis after 10 years of tight controlled treatment: a randomized trial. Ann Intern Med. 2016;164: 523-31.

43. Verschueren P, De Cock D, Corluy L, Joos R, Langenaken C, Taelman V, et al. Effectiveness of methotrexate with step-down glucocorticoid remission induction (COBRA Slim) versus other intensive treatment strategies for early rheumatoid arthritis in a treat-to-target approach: 1-year results of CareRA, a randomised pragmatic open-label superiority trial. Ann Rheum Dis. 2017;76: 511-20. 
44. Stouten V, Westhovens R, Pazmino S, De Cock D, Van der Elst K, Joly J, et al. Effectiveness of different combinations of DMARDs and glucocorticoid bridging in early rheumatoid arthritis: two-year results of CareRA. Rheumatology. 2019;58:2284-94.

45. ter Wee MM, den Uyl D, Boers M, Kerstens P, Nurmohamed M, van Schaardenburg D, et al. Intensive combination treatment regimens, including prednisolone, are effective in treating patients with early rheumatoid arthritis regardless of additional etanercept: 1-year results of the COBRA-light open-label, randomised, non-inferiority trial. Ann Rheum Dis. 2015;74:1233-40.

46. Dirven L, Bek M, Klarenbeek NB, Han KH, Ronday HK, Kerstens $\mathrm{P}$, et al. Eight year results of disease activity steered treatment in a large recent rheumatoid arthritis cohort: clinical and radiological outcomes. Arthritis Rheum Suppl. 2011;63(Suppl 10):2200.

47. Dirven L, van den Broek M, Klarenbeek NB, Van Krugten MV, Van Der Lubbe PAHM, Kerstens PJSM, et al. Seven year results of DAS steered treatment in the best study: clinical and radiological outcomes. Arthritis Rheum Suppl. 2010;62(Suppl 10):334.

48. Rantalaiho V, Korpela M, Hannonen P, Kautiainen H, Järvenpää S, Leirisalo-Repo M, et al. The good initial response to therapy with a combination of traditional disease-modifying antirheumatic drugs is sustained over time: the eleven-year results of the Finnish rheumatoid arthritis combination therapy trial. Arthritis Rheum. 2009;60:1222-31.

49. Bakker MF, Jacobs JW, Welsing PM, Vreugdenhil SA, van Booma-Frankfort C, Linn-Rasker SP, et al. Early clinical response to treatment predicts 5-year outcome in RA patients: follow-up results from the CAMERA study. Ann Rheum Dis. 2011;70: 1099-103.

50. Verstappen SM, Bakker MF, Heurkens AH, van der Veen MJ, Kruize AA, Geurts MA, et al. Adverse events and factors associated with toxicity in patients with early rheumatoid arthritis treated with methotrexate tight control therapy: the CAMERA study. Ann Rheum Dis. 2010;69:1044-8

51. Markusse IM, Dirven L, Van Groenendael JH, Han KH, Ronday HK, Kerstens PJSM, et al. Mortality in a large cohort of patients with early rheumatoid arthritis that were treated-to-target for 10 years (abstract). Arthritis Rheum. 2014;66:S359.

52. Klarenbeek NB, Güler-Yüksel M, van der Kooij SM, Han KH, Ronday HK, Kerstens PJ, et al. The impact of four dynamic, goal-steered treatment strategies on the 5-year outcomes of rheumatoid arthritis patients in the BeSt study. Ann Rheum Dis. 2011;70:1039-46.

53. den Uyl D, Ter Wee MM, Boers M, Voskuyl AE, Kerstens PJ, Nurmohamed MT, et al. Cobra-light therapy is clinically noninferior to original cobra therapy in the treatment of early rheumatoid arthritis. Ann Rheum Dis. 2013;71:104-5.

54. De Cock D, Westhovens R, Corluy L, Joos R, Langenaken C, Taelman V, et al. Comparison of MTX therapy with or without a moderate dose glucocorticoid bridging scheme in early rheumatoid arthritis patients lacking classical poor prognostic markers: week 16 results from the randomized multicenter carera trial. Ann Rheum Dis. 2014;73:220.

55. Verschueren P, Cock D, Corluy L, Joos R, Langenaken C, Taelman $\mathrm{V}$, et al. Patients lacking classical poor prognostic markers might also benefit from a step-down glucocorticoid bridging scheme in early rheumatoid arthritis: week 16 results from the randomized multicenter CareRA trial. Arthritis Res Ther. 2015;17:97.

56. De Cock D, Meyfroidt S, Joly J, Van der Elst K, Westhovens R, Verschueren P. For remission induction with glucocorticoid bridging, methotrexate monotherapy is as effective as a combination with other Dmards, with fewer reported side effects: 4 month primary outcome of Carera, a randomized induction strategy and treat to target trial in early rheumatoid arthritis. Arthritis Rheum. 2013;65: 3325-6.
57. Verschueren P, Cock D, Corluy L, Joos R, Langenaken C, Taelman $\mathrm{V}$, et al. Methotrexate in combination with other DMARDs is not superior to methotrexate alone for remission induction with moderate-to-high-dose glucocorticoid bridging in early rheumatoid arthritis after 16 weeks of treatment: the CareRA trial. Ann Rheum Dis. 2015;74:27-34.

58. Allaart CF, Breedveld FC, Dijkmans BA. Treatment of recent-onset rheumatoid arthritis: lessons from the BeSt study. J Rheumatol Suppl. 2007;34(Suppl 80):25-33.

59. Allaart CF, Geokoop-Ruiterman YPM, de Vries-Bouwstra JK, Breedveld FC, Dijkmans BAC. Aiming at low disease activity in rheumatoid arthritis with initial combination therapy or initial monotherapy strategies: the BeSt study. Clin Exp Rheumatol. 2006;24:S77-82.

60. Koevoets R, Dirven L, Klarenbeek NB, van Krugten MV, Ronday HK, van der Heijde DM, et al. Insights in the relationship of joint space narrowing versus erosive joint damage and physical functioning of patients with RA. Ann Rheum Dis. 2013;72:870-4.

61. van den Broek M, Dirven L, Klarenbeek N, Krugten M, Ronday H, Kerstens $\mathrm{P}$, et al. Clinical and radiological outcomes of four disease activity driven treatment strategies: 8-year results of the best study (abstract). Ann Rheum Dis. 2013;71:106. https://doi.org/10.1136/ annrheumdis-2012-eular.1837.

62. van den Broek M, Lems WF, Allaart CF. BeSt practice: The success of early-targeted treatment in rheumatoid arthritis. Clin Exp Rheumatol. 2012;30(Suppl 4):S35-8.

63. van der Kooij SM, de Vries-Bouwstra JK, Goekoop-Ruiterman YP, Ewals JA, Han KH, Hazes JM, et al. Patient-reported outcomes in a randomized trial comparing four different treatment strategies in recent-onset rheumatoid arthritis. Arthritis Rheum. 2009;61:4-12.

64. National Institute for Health and Care Excellence. Guide to the Methods of Technology Appraisal. London: NICE; 2013.

65. Jalal H, O’Dell JR, Bridges SL Jr, Cofield S, Curtis JR, Mikuls TR, et al. Cost-effectiveness of triple therapy versus etanercept plus methotrexate in early aggressive rheumatoid arthritis. Arthritis Care Res. 2016;68:1751-7.

66. Smolen JS. Treat to target in rheumatology: a historical account on occasion of the 10th anniversary. Rheum Dis Clin N Am. 2019;45: 477-85.

67. Singh JA, Saag KG, Bridges SL Jr, Akl EA, Bannuru RR, Sullivan MC, et al. 2015 American College of Rheumatology guideline for the treatment of rheumatoid arthritis. Arthritis Rheum. 2016;68:126.

68. Bykerk V, Akhavan P, Hazlewood GS, Schieir O, Dooley A, Haraoui B, et al. Canadian Rheumatology Association recommendations for pharmacological management of rheumatoid arthritis with traditional and biologic disease-modifying antirheumatic drugs. J Rheumatol. 2012;39:1559-82.

69. Gaujoux-Viala C, Gossec L, Cantagrel A, Dougados M, Fautrel B, Mariette X, et al. Recommendations of the French Society for Rheumatology for managing rheumatoid arthritis. Joint Bone Spine. 2014;81:287-97.

70. Smolen JS, Landewé R, Bijlsma J, Burmester G, Chatzidionysiou $\mathrm{K}$, Dougados M, et al. EULAR recommendations for the management of rheumatoid arthritis with synthetic and biological diseasemodifying antirheumatic drugs: 2016 update. Ann Rheum Dis. 2017;76:960-77.

71. Gvozdenović E, Allaart CF, van der Heijde D, Ferraccioli G, Smolen JS, Huizinga TW, et al. When rheumatologists report that they agree with a guideline, does this mean that they practise the guideline in clinical practice? Results of the International Recommendation Implementation Study (IRIS). RMD Open. 2016;2:e000221.

72. Glauser TA, Ruderman EM, Kummerle D, Kelly S. Current practice patterns and educational needs of rheumatologists who manage patients with rheumatoid arthritis. Rheumatol Ther. 2014;1:31-44. 
73. Curtis JR, Chen L, Danila MI, Saag KG, Parham KL, Cush JJ. Routine Use of quantitative disease activity measurements among US rheumatologists: implications for treat-to-target management strategies in rheumatoid arthritis. J Rheumatol. 2018;45:40-4.

74. Aletaha D, Alasti F, Smolen JS. Optimisation of a treat-to-target approach in rheumatoid arthritis: strategies for the 3-month time point. Ann Rheum Dis. 2016;75:1479-85.

75. Bacalao EJ, Greene GJ, Beaumont JL, Eisenstein A, Muftic A, Mandelin AM, et al. Standardizing and personalizing the treat to target (T2T) approach for rheumatoid arthritis using the PatientReported Outcomes Measurement Information System (PROMIS): baseline findings on patient-centered treatment priorities. Clin Rheumatol. 2017;36:1729-36.

76. Solomon DH, Losina E, Lu B, Zak A, Corrigan C, Lee SB, et al. Implementation of treat-to-target in rheumatoid arthritis through a learning collaborative: results of a randomized controlled trial. Arthritis Rheum. 2017;69:1374-80.

77. Jurgens MS, Welsing PM, Jacobs JW. Overview and analysis of treat-to-target trials in rheumatoid arthritis reporting on remission. Clin Exp Rheumatol Suppl. 2012;30(Suppl 4):S56-63.

78. Schipper LG, van Hulst LT, Grol R, van Riel PL, Hulscher ME, Fransen J. Meta-analysis of tight control strategies in rheumatoid arthritis: protocolized treatment has additional value with respect to the clinical outcome. Rheumatol. 2010;49:2154-64.

79. Bakker MF, Jacobs JW, Verstappen SM, Bijlsma JW. Tight control in the treatment of rheumatoid arthritis: efficacy and feasibility. Ann Rheum Dis Suppl. 2007;66(Suppl 3):iii56-60.
80. Knevel R, Schoels M, Huizinga TWJ, Aletaha D, Burmester GR, Combe B, et al. Current evidence for a strategic approach to the management of rheumatoid arthritis with disease-modifying antirheumatic drugs: a systematic literature review informing the EULAR recommendations for the management of rheumatoid arthritis. Ann Rheum Dis. 2010;69:987-94.

81. Rantalaiho V, Korpela M, Laasonen L, Kautiainen H, Järvenpää S, Hannonen P, et al. Early combination disease-modifying antirheumatic drug therapy and tight disease control improve long-term radiologic outcome in patients with early rheumatoid arthritis: the 11-year results of the Finnish Rheumatoid Arthritis Combination Therapy trial. Arthritis Res Ther. 2010;12:R122.

82. Rantalaiho V, Puolakka K, Korpela M, Hannonen P, Mottonen T. Long-term results of the FIN-RACo trial; treatment with a combination of traditional disease-modifying anti-rheumatic drugs is an excellent option in early rheumatoid arthritis. Clin Exp Rheumatol. 2012;30:S27-31.

83. Goekoop-Ruiterman YP, de Vries-Bouwstra JK, Allaart CF, van Zeben D, Kerstens PJ, Hazes JM, et al. Comparison of treatment strategies in early rheumatoid arthritis - a randomized trial. Ann Intern Med. 2007;146:406-15.

Publisher's Note Springer Nature remains neutral with regard to jurisdictional claims in published maps and institutional affiliations. 